DOI URL: https://doi.org/10.3126/jbssr.v5i1.30200

\title{
An Analysis of Motivational Factors Affecting Employee Performance
}

\section{Pooja Dangol ${ }^{1}$}

Article History

Received 20 Jan 2020

Reviewed 3 March 2020

Revised 20 April 2020

Revised-2nd 06 May 2020

Accepted 27 May 2020

\section{Keywords}

employee performance; monetary rewards; goal-setting; recognition programmes; trainings

Journal of Business and Social Sciences Research (ISSN: 25422812). Vol V, No. 1, June 2020

\section{Abstract}

It is essential for organisations to pay attention to the well-being of their employees. The organisation should create a workplace that is engaging and motivating, where employees want to stay, grow and contribute their skills, knowledge and expertise. The present research study aims to investigate motivational factors (goal-setting, monetary rewards, recognition programmes and training) that aids in upsurge of employee performance. The study adopted a descriptive research design. The population consists of 130 employees of 30 companies of Nepal. Data was collected using structured questionnaires. Statistical tools such as frequency distribution, mean score, correlation analysis and regression analysis were used to analyse data and were presented using tables. The results reveal that there exists a positive and significant relationship between goal-setting, recognition programmes and training on employee performance. The findings suggest that employees value their own personal growth. Organisations should come up with personal development programmes to improve performance. The study results are expected to offer inputs in assessing and implementing motivational factors in organisations.

\section{Introduction and Study Objectives}

Nowadays, one of the major concerns for any organisation is to motivate its employees and make best use of human resources. An important role of management is to help make work more satisfying and rewarding for employees and to make employee motivation consistent with organisational objectives (Uzonna, 2013). Employees are considered as one of the most valuable assets of an organisation who is responsible to perform various organisational tasks. Organisations expect new innovative ideas, business plans and strategies from the employees so that it can expand its business with improved performance.

${ }^{1}$ Ms. Dangol is an MBA graduate from KUSOM, Kathmandu University and is currently an HR Professional. She can be contacted at pujadngo|@gmail.com 
With knowledge, skill and ability of the employees, any organisation can opt for new opportunities.

Employee motivation is one of the most important management functions among the employees, in order to perform in full potential of their abilities (Dell, 2019). The key to an organisational success depends upon its people. A motivated and goaldriven employee tends to work with full energy and passion to accomplish his/her goals. S/he will look for opportunities to contribute more in the organisation and bring a commendable change in the business. Hence, motivation and performance are linked with each other. Organisations should look for ways to find out factors which makes its employees motivated so that they are willing to contribute in achieving short and long-term organisational goals. Employee motivation is the process of stimulating people to actions, further to accomplish goals (Heryati, 2016). Organisations spend a lot of time identifying factors that motivates its employees. Motivation is seen as one of the four most important factors in issues related to human resources management (HRM) and organisational behaviour management (Nelson \& Quick, 2013). Motivation is about identifying the need of human resources and bringing an impact in one's actions that integrates his/ her behaviour. This research is imperative to identify factors causing hindrance in employees' performance. It will help to figure out proper motivation strategies that the HR Managers can use to populate its workforce with motivated and committed employees.

With the increase in the number of competitors in the similar line of business, it is essential for companies to identify effective motivational strategies and increase productivity. Performance is a function of job opportunities (such as knowledge, capabilities, and skills that workers need for the realisation of their duties), motivation (benefits that workers seek for their motivation) and organisation of work (how work and organisations are structured that enable employees perform better) (Boxall \& Purcell, 2011). Therefore, research has carried out to find out motivational factors that enhance performance of employees.

The remaining sections of the paper are organised as follows. The second section deals with reviewing existing literature that primarily deals with discussions and review of literature related to the concepts of the research. The third section describes methodology adopted for the study. Fourth section comprises compilation, analysis and discussion of data collected from research. Fifth section consists of concluding remarks and the sixth section comprises implications of the research study.

\section{Literature Review}

Human Resource Management is a typical new approach to management of personnel which attempts to obtain competitive advantage through a highly committed and skilled workforce (Storey, 1992). HRM is managing (planning, organising, directing and controlling) the functions of employing, developing, 
compensating and utilising human resources (Rao, 2009). With more and more people from diversified cultures working together in one organisation, it becomes essential for HR Managers to bring synergy from these multi-talented people and increase efficiency. Human resource management focuses on the people in an organisation, and is a function of management that deals with hiring, motivating and retaining people in an organisation (Ismajli, Qosja, \& Krasniqi, 2015).

In today's knowledge-based competitive environment, organisations must mobilise and motivate its employees to identify their hidden skills and inculcate creative business ideas which will maximise organisational profits. The available resources for organisations or institutions are: human, financial, physical and information resources (Banfield \& Kay, 2012). Organisation will have to know values, cultures, personal goals, skills and competencies of employees to understand the driving factor. Each individual is unique and it is tough for managers to understand their human behaviour. In this regard, one question often raised by managers is, "What makes the employees of an organisation go the extra mile to deliver exemplary performance?"

Human nature is varied and if HR can understand the psychological aspects of its employees and use motivational techniques accordingly; it will bear long-term fruitful outcomes through constructive contribution of the workforce. A satisfied employee does not work because he is forced to, rather because he enjoys his work (Dell, 2019). While doing so, HR personnel need to keep in mind both present as well as future requirements of the organisation along the set plans and objectives that it was identified for the purpose of attainment of goals. Only after this, the organisation can move onto the path of growth and development and reach new heights.

Motivation for the entry level staff would be different from that of managerial level and the employees of different cultures and values. Various theories of motivation encompass the tools and techniques that stimulate the desire of human resources to deliver excellent performance at the workplace. Motivation imposes employee outcomes for instance performance and productivity (Grant, 2008). He recognised that motivated employees are more oriented towards autonomy and are more selfdriven in contrast to less motivated employees (Grant, 2008). Further, motivated employees are highly engaged and involved in their work and jobs and are more willing to take responsibilities (Kuvaas \& Dysvik, 2009).

Employee performance is the activity ofperforming something fruitfully by knowledge as famous from simply possessing it (Nasibov, 2015). Managers play a crucial role in founding a conducive environment where there is presence of cohesive team members who acknowledge each other for their contribution. Both short and longterm goals of the organisation can be attained if co-ordination and co-operation takes place simultaneously which can be effectively done through motivation. Organisations can develop KPIs and KRAs that help to motivate employees to achieve targets. The incentive awards like medals would be less important than the process of continuous self-improvement (Saric, 2016). 
The Maslow's need hierarchy advocates that growth is the most prominent motivating factor. Young leaders highly value growth careers and are always looking for ways to move ahead in their career. Organisations should bring career development programmes and show growth opportunities through rewarding jobs to bring the best out of the employees. Individual at its initial level of its career pays high values to intrinsic and extrinsic features related to their job. Moreover, individuals with the start-up of their careers valued the rewarding towards their work assessment and environment further the expert and experienced individuals with high potential and opportunities also provide values (Khan, Ahmed, Paul, \& Alam, 2017).

Organisations spend huge investments in training and development. It is of utmost importance that employees not only have a good relationship with the top management, but also, they maintain a healthy and professional relationship with their co-workers (Nabi, Islam, Dip, \& Hossain, 2017). Assessing culture of the organisation and conducting team building activities help to strengthen bond with team members. Timely training and development on identified aspects is an obligation to the management of the organisation so that err is minimised and hence there is an increase in productivity of employees. Training and development play a contributing factor keeping employees motivated throughout.

Workplace motivators consist of monetary and non-monetary incentives (Perrin, 2007). Incentives are highly practised in organisations that have pay-based culture or high-performance culture. Monetary incentives include profit sharing, project bonuses, schedule bonuses and additional paid vacation time. Similarly, nonmonetary reward incentives include flexible work hours, training opportunities, pleasant work environment, and sabbatical leaves. Reward practices (monetary and non-monetary) have been found to be positively linked to organisational performance as they help maintain a positive motivational environment relevant in improving organisational performance (Perrin, 2007).

Since the beginning of the modern management theory, the terms used to describe the HRM have included personnel and staff, industrial and employee relations and human resource management (Carbery \& Cross, 2013). With the right amount of organisation looking onto the people management aspect, organisations can witness engaged and motivated employees at work. It is one of the most effective ways to create the desired impact which is done through hard work and admiration which boosts the ability for companies to achieve their goals. It is crucial for organisations to manage and attract potential and creative minds.

With the pace in which the world is moving forward, the motivational factors that were identified long back would not be applicable at present. Organisations are operated with the team that includes people with diversified culture and values. Young minds would not prefer the same primitive motivational factors that were used long back. This research is imperative to identify both intrinsic as well as 
extrinsic sources of motivation. This research is aimed to identify improved and effective sources of motivation that the businesses can practise.

The framework hypotheses linkages between various constructs derived from different literatures on motivation. The conceptual framework is shown below:

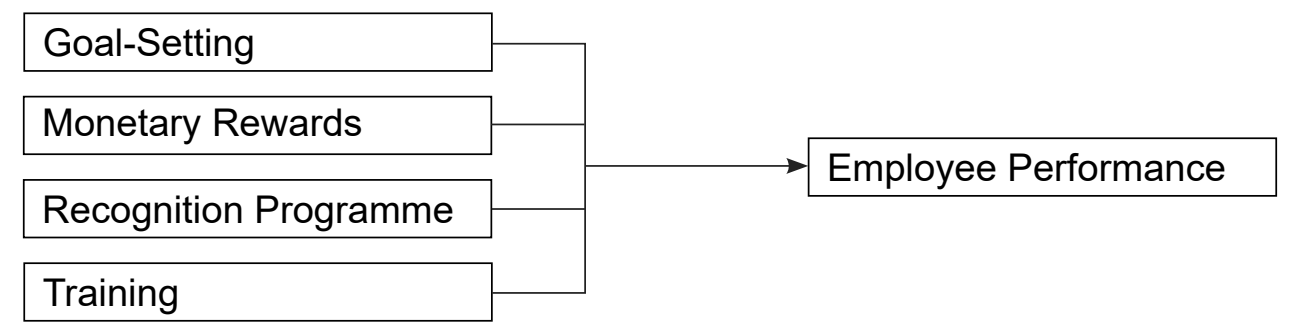

Independent Variables Dependent Variable

Figure 1: Conceptual Framework

\section{Research Methods}

\section{Nature and Collection of Data}

The nature of present research is quantitative. Descriptive study was conducted to identify motivational factors and statistical tools was used to prove and validate through hypothesis testing. Four motivational factors were concluded to be as the main principle factors than other remaining factors.

The study setting in which the research was conducted was non-contrived. The total population of this research is 250. The researcher included only those employees who were available to participate in the survey. Convenience sampling method was used for the research. 130 employees of 30 organisations were taken as a unit of analysis. The total sample size is 130 .

The present research work is based on both primary and secondary data. Various secondary sources used include books and articles, which appeared in journals. Primary data have been collected with the help of a non-disguised structured questionnaire. Data collected in this study was by means of a structured questionnaire.

A carefully fit organised questionnaire was created by the researcher for this study. There were four constructs for Likert scale questions where respondents were asked questions related with each construct. Individual employee responses were collected and data from the sample were analysed to find out the result of the study. Quantitative data were gathered from each employee and each of their responses were treated as an individual data source.

Descriptive statistics was used in the research to identify and understand the demographic profile of the respondents. The researcher wanted to check the relevancy of data and the results generated through the same and varied 
demographic profile. Similarly, mean score has been used to identify the average value of distribution of figures. The researcher used this tool to compare different sets of data.

Correlation analysis was used to study if there are possible connections between variables. The study has checked the degree of a positive and negative relationship to come into conclusion. The researcher has used regression analysis to examine the relationship and influence between one or more identified variables with one another. Similarly, ANOVA tables have been used to determine the nature of significance between identified variables.

\section{Discussion}

The study has employed descriptive analysis for describing the data and correlation, ANOVA Test and regression analysis among other statistical tools to analyse data. The results from the statistical tests of significance are presented and analysed in subsequent sections.

\section{Response Rate}

Table 1 is indicative of the results which were obtained from the demographic profile. It consists of four dimensions- gender, age group, level of management and years of association. It was found that 42.30 per cent of the respondents were female and 57.70 per cent were male. It shows male respondents higher than female respondents.

Table 1

Demographic Profile of the Study Variables

\begin{tabular}{llll}
\hline Variable & Classification of Variables & $\mathrm{N}$ & $\%$ \\
\hline Gender & Female & 55 & 42.30 \\
& Male & 75 & 57.70 \\
Age Group & Below 25 & 33 & 25.38 \\
& $25-30$ & 48 & 36.92 \\
& $31-35$ & 23 & 17.69 \\
& $36-40$ & 11 & 8.46 \\
Level & 41 and above & 15 & 11.55 \\
of Management & Entry Level & 30 & 23.07 \\
& Lower Middle Level & 21 & 16.15 \\
Years of Association & Middle Level & 42 & 32.30 \\
& Upper Level & 37 & 28.48 \\
& Less than 1 year & 20 & 15.38 \\
& 1-2 years & 32 & 24.61 \\
& 3-5 years & 37 & 28.46 \\
& 6-10 years & 23 & 17.69 \\
& More than 10 years & 18 & 13.86 \\
\hline
\end{tabular}

Note. From researcher's survey, 2019 
It was found that 23.07 per cent of the respondents were from entry level management, 16.15 percent were lower middle level management, 32.30 per cent were middle level management and 28.48 per cent of the respondents were upper level management.

Descriptive statistics for years of association of the respondents showed that majority of respondents are associated with for 3-5 years, which is 28.46 per cent of the respondents.

\section{Maximum, Minimum and Mean Values}

Table 2

Descriptive Statistics of Study Variables

\begin{tabular}{llllll}
\hline & $\mathrm{N}$ & Min & Max & Mean & Std. D \\
\hline Goal-setting & 130 & 1.60 & 4.80 & 3.71 & 0.56 \\
Monetary Rewards & 130 & 1.60 & 4.40 & 3.34 & 0.49 \\
Recognition Programmes & 130 & 1.70 & 4.70 & 3.45 & 0.57 \\
Training & 130 & 1.60 & 5.00 & 3.56 & 0.81 \\
Employee Performance & 130 & 1.60 & 4.50 & 3.38 & 0.51 \\
\hline
\end{tabular}

Note. Calculations based on researcher's survey, 2019

The result in table 2 shows that employees' overall means score for Employee Performance is 3.38 (S.D. $=0.51$ ). It suggests that employee performance in their workplace is around average. Similarly, mean values for goal-setting, monetary incentive, reward and recognition, training and development and employee performance are $3.71,3.34,3.45,3.56$ and 3.38 respectively. This shows all the four factors have mean values around the average.

Gender, Goal Setting, Monetary Incentive, Reward, Training and Employee Performance

Table 3

Group Statistics- Gender

\begin{tabular}{lllll}
\hline Variables & Gender & $\mathrm{N}$ & Mean & Std. D \\
\hline Goal-setting & Female & 54 & 3.82 & 0.40 \\
Monetary Rewards & Male & 76 & 3.63 & 0.64 \\
& Female & 54 & 3.51 & 0.40 \\
Recognition Programmes & Male & 76 & 3.21 & 0.51 \\
& Female & 54 & 3.68 & 0.49 \\
Training & Male & 76 & 3.28 & 0.57 \\
& Female & 54 & 3.55 & 0.96 \\
Employee Performance & Male & 76 & 3.58 & 0.69 \\
& Female & 54 & 3.42 & 0.46 \\
& Male & 76 & 3.36 & 0.54 \\
\hline
\end{tabular}

Note. Calculations based on researcher's survey, 2019 
The results in table 3 shows mean values of male and female employees with various other variables. The mean score of female employees in goal-setting is 3.82 , monetary rewards is 3.51 , recognition programmes is 3.68 , training is 3.55 and employee performance is 3.42. Similarly, mean scores of male employees in goalsetting is 3.63 , monetary reward is 3.21 , recognition programme is 3.28 , training is 3.58 and employee performance is 3.36 . It suggests that the mean score of female employees is higher than male in employee performance. In regards to training and development, it was higher in male than in female while motivational goal setting, monetary incentive and reward and recognition were higher in female than in male.

\section{Correlation Analysis}

Table 4

Correlation between Dependent and Independent Variable

\begin{tabular}{|c|c|c|c|c|c|}
\hline & Goal-setting & $\begin{array}{l}\text { Monetary } \\
\text { Rewards }\end{array}$ & Recognition & Training & $\begin{array}{l}\text { Employee } \\
\text { Performance }\end{array}$ \\
\hline \multirow[t]{2}{*}{ Goal-setting } & & $0.65^{* *}$ & $0.51^{\star *}$ & $0.45^{\star \star}$ & $0.49^{* *}$ \\
\hline & & 0.00 & 0.00 & 0.00 & 0.00 \\
\hline \multirow[t]{2}{*}{ Monetary Rewards } & & 1.00 & $0.75^{\star *}$ & $0.33^{* *}$ & $0.39^{\star *}$ \\
\hline & & & 0.00 & 0.00 & 0.00 \\
\hline \multirow[t]{2}{*}{ Recognition } & & & 1.00 & $0.31^{* *}$ & $0.46^{* \star}$ \\
\hline & & & & 0.00 & 0.00 \\
\hline \multirow[t]{2}{*}{ Training } & & & & 1.00 & $0.45^{\star *}$ \\
\hline & & & & & 0.00 \\
\hline Employee Performance & & & & & 1.00 \\
\hline
\end{tabular}

**. Correlation is significant at the 0.01 level (2-tailed).

Note. Calculations based on researcher's survey, 2019

As significance level is 0.00 which is less than 0.05 , therefore, the alternative hypothesis is accepted. That means to say, increase or decrease in independent variables significantly relate to increase or decrease in dependent variable employee performance.

\section{Regression Analysis}

On the basis of the above finding regression analysis has been developed:

$\hat{y}=1.29+0.26 \times 1-0.13 \times 2+0.29 \times 3+0.16 \times 4$

Where,

X1=Goal-setting

$\mathrm{X} 2=$ Monetary Rewards

$\mathrm{X} 3=$ Recognition

$X 4=$ Training

$\hat{y}=$ Employee Performance 
From Table 5, we can see that the coefficient of determination ( $R$ square) is 0.36 . This shows that there is only 36 per cent of variation in the dependent variable and the remaining 64 per cent is due to other factors.

Table 5

Regression Analysis of Different Variables

\begin{tabular}{lllll}
\hline & $\mathrm{B}$ & T-Value & P-Value & VIF \\
\hline (Constant) & 1.29 & 4.61 & 0.00 & \\
Goal-setting & 0.26 & 2.85 & 0.01 & 1.96 \\
Monetary Rewards & -0.13 & -1.06 & 0.29 & 2.93 \\
Recognition & 0.29 & 3.03 & 0.00 & 2.30 \\
Training & 0.16 & 3.21 & 0.00 & 1.27 \\
\hline R-Square & 0.36 & & & \\
Adjusted R-Square & 0.34 & & & \\
F & 17.36 & & & \\
P-Value & $0.00 \mathrm{~b}$ & & & \\
\hline
\end{tabular}

${ }^{b} \mathrm{P}$-value were obtained by two sample t-tests.

Note. Calculations based on researcher's survey, 2019

Since significance value is less than the alpha value of 0.05 (95\% confidence interval), we do not accept the null hypothesis. Therefore, a linear relationship exists between the dependent variable and at least one of the independent variables.

\section{Hypothesis Testing}

At the $5 \%$ level of significance,

P-value $=0.005<\alpha=0.05$, hence, we do not accept null hypothesis. This indicates goal-setting (x1) is a significant independent variable for employee performance $(\mathrm{y})$.

$P$-value $=0.292>\alpha=0.05$, hence, we fail to reject null hypothesis. This indicates monetary rewards $(\mathrm{x} 2)$ is not a significant independent variable for employee performance $(\mathrm{y})$.

P-value $=0.003<\alpha=0.05$, hence, we do not accept null hypothesis. This indicates recognition programmes $(x 3)$ is a significant independent variable for employee performance $(\mathrm{y})$.

$P$-value $=0.002<\alpha=0.05$, hence, we do not accept null hypothesis. This indicates training ( $\mathrm{x} 4)$ is a significant independent variable for employee performance $(\mathrm{y})$.

\section{Conclusion and Implications}

The present research study showed that employees valued goal-setting, recognition programmes and training as a motivating element for better 
performance. The results are contrary to initial findings and speculations of the researcher during preliminary survey. Previous research works on the motivational factors expressed monetary rewards as a motivating factor among other factors. But the results in this study show that employees feel encouraged and motivated in the workplace after knowing their career growth and development.

Results demonstrate shift towards agile organisations who value skills and competencies of employees rather than experience, flexible work from home culture, switch from traditional corporate setting to more casual culture and the organisations who foster innovation. We can see many IT giants such as Google have started to adopt such a culture and have initiated a learning academy where employees can join developmental programmes right from their induction. Such organisations provide a clear glimpse of career advancements.

The findings of this research study may help in implementing motivational strategies to improve organisational effectiveness. This research gives significant contribution to organisations by providing a detailed status of motivational environment and in what areas does improvement is needed. Overall, The study results can offer inputs in assessing and implementing motivational factors in organisations

The present research was conducted in a limited sample population. It includes employees who work in Nepal. The results that have been generated from this research may not be applicable in other countries. Motivational factors are completely unique from one individual to another and it might change with the passage of time. The results generated may be biased as well since it is conducted in a one-shot survey.

However, this research acts as a basis for further research on motivational factors. This study reveals the motivation factors which affect employee performance. Some unanswered questions have been exposed such as the connection between development activities with employee performance and change in organisational culture.

There is the need for future researchers to conduct further research on this topic. While working in this research, there were a handful of research in existence. Identifying and coming into conclusion on this rising topic will definitely bring a commendable change in the corporate business world.

\section{References}

Banfield, P., \& Kay, R. (2012). Introduction to human resources management ( $2^{\text {nd }}$ ed.). United Kingdom: Oxford University. Retrieved from: https://westminster.rl.talis.com/ items/92547117-5158-5CEE-B6D5-406F8DF826D7.html

Boxall, P., \& Purcell, J. (2011). Strategy and human resource management: Management, work and organisations ( $3^{\text {rd }}$ ed.). New York: Palgrave Macmillan. Retrieved from: http://CQU.eblib.com/patron/FullRecord.aspx?p=619533 
Carbery, R., \& Cross, C. (2013). Human resource management ( $2^{\text {nd }}$ ed.). United Kingdom: Red Globe Press. https://www.macmillanihe.com/page/detail/HumanResource Management/?K=9781352004021

Deci, E. L. (2013). Intrinsic motivation. New York, NY: Plennum Press. Retrieved from: https://www.worldcat.org/title/intrinsic-motivation/oclc/1500344

Dell, M. (2019). Impact of BYOD on organizational commitment: An empirical investigation, information technology and people, 32(2), 246-268. https:// www.deepdyve.com/lp/emerald -publishing/impact-of-byod-on-organizationalcommitment-an-empirical-investigation pYbcyKMFCC impressionld=5 d9884220aa12\&i_medium=docview\&i_campaign=recommendati ns\&i source=recommendations

Grant, A. M. (2008). Does intrinsic motivation fuel the pro-social fire? Motivational synergy in predicting persistence, performance, and productivity. Journal of Applied Psychology, 93(1), 48-58. Retrieved from: http://selfdeterminationtheory. org/SDT/documents/2008_Grant_

Heryati, R. (2016). Why employee motivation is important and how to improve it. Retrieved from:https://inside.6q.io/employee-motivation-important/

Ismajli, N., Qosja, E., \& Krasniqi, I. (2015). The importance of motivation factors on employee performance in Kosovo municipalities. Journal of Public Administration and Governance, 5(1), 2161-7104. Retrieved from: https://www.researchgate.net/ publication/ 273495322_The_Importance_of_Motivation_Factors_onEmployee_ Performance_in_Kosovo_Municipalities

Khan, A., Ahmed, S., Paul, S., \& Alam, S. H. (2017). Factors affecting employee motivation towards employee performance: A study on banking industry of Pakistan. Proceedings of the Eleventh International Conference on Management Science and Engineering Management. 615-625. Retrieved from: https:// mpra.ub.uni-muenchen.de/80930/ Kuvaas, B., \& Dysvik, A. (2009). Perceived investment in employee development, intrinsic motivation and work performance. Human Resource Management Journal, 19(3), 217-236. Retrieved from: https:// onlinelibrary.wiley.com/doi/abs/10.1111/j.1748-8583.2009.00103.x

Nabi, M. N., Islam, M. M., Dip, T. M., \& Hossain, M. A. A. (2017). Impact of motivation on employee performances: A case study of Karmasangsthan bank limited, Bangladesh. Arabian Journal of Business and Management Review, 7(1). Retrieved from: https://www.hilarispublisher.com/open access/impact-ofmotivation-on-employee performances -a-case-study-of-karmasangsthan-bank limited-bangladesh Nasibov, A. (2015). Impact of employee motivation on performance (productivity). Journal of Human Resource Management, 4(1), 1521. Retrieved from: https://www.linkedin.com/pulse/impact -employee-motivationperformance-productivity-anar-nesibov/

Nelson, D. L., \& Quick, J. C. (2013). Principles of organisational behavior: realities and challenges ( $8^{\text {th }}$ ed.). Ohio: South-Western. Retrieved from: https://www. worldcat.org/title/principles-of-organizational-behavior-realities-and-challenges/ oclc/779244912

Perrin, T. (2007). Reward management: Closing a growing say/do gap. Towers Perrin. Retrieved from: https://www.scribd.com/document/13999152/RewardManagement-Closing-Growing-SayDo-Gap 
Rao, P. S. (2009). Personnel and human resource management. New Delhi: Himalaya Publishing House. Retrieved from: https://www.academia.edu/38318720/ chapter850-pdf_4485794.pdf

Saric, M. (2016). Dan pink: The puzzle of motivation, a summary. Retrieved from: http://mayasaric.com/dan-pink-the-puzzle-of-motivation-a-summary/

Storey, J. (1992). Developments in the management of human resources: An analytical review (Warwick studies in industrial relations). Retrieved from: https://www.wiley. com/en-us/+in+the+Management+of+Human+Resources\%3A+An+Analytical+Rev iew-p-9780631183983

Uzonna, U. R. (2013). Impact of motivation on employee performance: A case study of credit west bank Cyprus. Journal of Economics and International Finance, 5(5), 199-211. Retrieved from: https://academicjournals.org/journal/JEIF/article-abstract/ A85765D28566

\section{Acknowledgements}

The author acknowledges the support of Asst. Prof. Seema Singh.

Conflict of interest

All opinions presented in this research belong to the author alone, and not any institution.

The author declares having no conflicting interest. 